\title{
Previous Gestational Diabetes Mellitus and Markers of Cardiovascular Risk
}

\author{
Nikolaos Vrachnis, ${ }^{1,2}$ Areti Augoulea, ${ }^{1,2}$ Zoe Iliodromiti, ${ }^{1}$ Irene Lambrinoudaki, \\ Stavros Sifakis, ${ }^{3}$ and George Creatsas ${ }^{1}$
}

${ }^{1}$ 2nd Department of Obstetrics and Gynecology, University of Athens Medical School, Aretaieio Hospital, 11526 Athens, Greece

${ }^{2}$ Obstetric and Gynecological Unit and Research Center, Evgenideio Hospital, University of Athens, 11526 Athens, Greece

${ }^{3}$ Department of Obstetrics and Gynaecology, University Hospital of Heraklion, 71110 Heraklion, Crete, Greece

Correspondence should be addressed to Nikolaos Vrachnis, nvrachnis@med.uoa.gr

Received 22 November 2011; Revised 6 January 2012; Accepted 10 January 2012

Academic Editor: Andrea Tura

Copyright (๑) 2012 Nikolaos Vrachnis et al. This is an open access article distributed under the Creative Commons Attribution License, which permits unrestricted use, distribution, and reproduction in any medium, provided the original work is properly cited.

The prevalence of gestational diabetes mellitus (GDM) in the developed world has increased at an alarming rate over the last few decades. GDM has been shown to be associated with postpartum diabetes, insulin resistance, hypertension, and dyslipidemia. A history of previous GDM (pGDM), associated or not with any of these metabolic abnormalities, can increase the risk of developing not only type 2 diabetes mellitus but also cardiovascular disease (CVD) independent of a diagnosis of type 2 diabetes later in life. In this paper we discuss the relationship among inflammatory markers, metabolic abnormalities, and vascular dysfunction in women with pGDM. We also review the current knowledge on metabolic modifications occurring in normal pregnancy and the link between alterations of a normal metabolic state with the long-term maternal complications that may result in increased CVD risk. Our review of studies on pGDM prompts us to recommend that these women be considered a population at risk for later CVD events, which however could be avoided via the use of specially designed follow-up programs in the future.

\section{Introduction}

Gestational diabetes mellitus (GDM) is any degree of glucose intolerance with onset or first recognition during pregnancy $[1,2]$. In early gestation fasting blood glucose is lower and insulin sensitivity decreases slightly. This is followed by progressively increasing insulin resistance in the second and third trimesters with a borderline increase of insulin production or hyperinsulinemia. Furthermore, insulin resistance occurs as a result of placental hormones that antagonize insulin, estrogen, progesterone, human placental lactogen (HPL), human placental growth hormone, cortisol, prolactin, and tumor necrosis factor-alpha (TNF- $\alpha$ ) [3]. The above different pathophysiologic mechanisms accompanying pregnancy result in metabolic changes that allow for higher postprandial maternal glucose. Pregnancy is a hyperinsulinemic state which may develop into impaired glucose tolerance if insulin secretion is unable to compensate for pregnancyassociated insulin resistance [3-5].
The condition of GDM is a state of chronic lowgrade subclinical inflammation characterized by abnormal production of cytokine and mediators and activation of a network of inflammatory signaling pathways. Although the characteristic of GDM is insulin resistance, the exact mechanism involved in this process is still unknown. The increased insulin resistance during pregnancy has been, as just described, attributed to cortisol and gestational hormones, but more recent data have shown that cytokines may also be involved in this process [6]. The most significant maternal risk is that of development of metabolic syndrome characterized by central obesity, dyslipidemia, and insulin resistance, which predispose to increased risk for coronary artery disease, stroke, and type 2 diabetes later in life [7-11].

The incidence of type 2 diabetes in women with previous GDM (pGDM) who were examined six weeks to 28 years postpartum was estimated to range from $2.6 \%$ to $70 \%$ $[12,13]$. Other researchers found that women with $\mathrm{pGDM}$ have a $18-50 \%$ risk of developing type 2 diabetes mellitus 


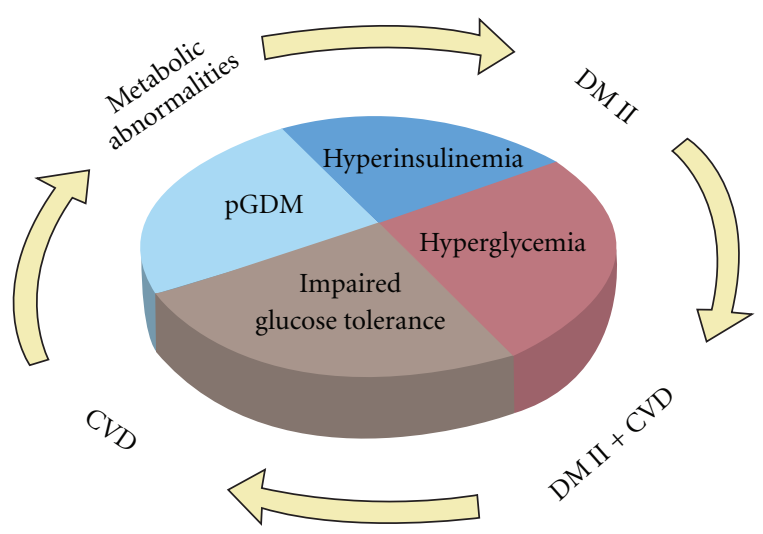

FIGURE 1: Metabolic status during pregnancy and pGDM may result in outcomes later in life like metabolic abnormalities, DMII, CVD, and DMII + CVD as it is shown following the arrows.

within 5 years following pregnancy [14-17], and diabetes is an established risk factor for CVD $[18,19]$. In addition, women with a history of GDM are at increased risk of other cardiovascular risk factors, such as obesity, hypertension, dyslipidemia, and subclinical atherosclerosis [20-22]. It is unclear whether women with a history of GDM who do not subsequently develop type 2 diabetes mellitus are also at an increased CVD risk in the future. The metabolic abnormalities which accompany GDM preceding type 2 diabetes and which remain in effect during the natural course of the disease place women at high risk for CVD [23].

In this paper we review the interrelationship among inflammatory markers, metabolic abnormalities, and endothelium dysfunction in pGDM and discuss whether these women could be considered at risk for cardiovascular disease later in life. Based on the small amount of existing literature, we discuss the inflammatory and metabolic abnormalities underlying the status of PGDM and the potential that endothelial dysfunction is a marker of future CVD risk. To our knowledge, this is the first paper presented in the literature dealing with markers of CVD risk in women with a history of gestational diabetes.

\section{Surrogate Markers of Increased Cardiovascular Risk}

Although the majority of women with GDM return to normal glucose tolerance after delivery, they remain, as a group, at substantially increased risk of developing type 2 diabetes in later life, a known condition that leads to an increased risk for CVD [24].

Inflammation may contribute to atherosclerosis by a variety of mechanisms depending on the stage of the disease. Circulating markers of systemic inflammation have been shown to predict future CVD [25]. These markers include Creactive protein (CRP), proinflammatory cytokines such as interleukin-6 (IL-6), and soluble adhesion molecules. Most attention has been focused on CRP which, along with IL-6, has been revealed in large prospective studies to be a consistent predictor of future cardiovascular events [26, 27].

Epidemiological and experimental studies have established the association of markers of subclinical inflammation with CVD, type 2 diabetes, and metabolic syndrome (Figure 1). Pregnancy is a hyperinsulinemic state in which the increased insulin resistance during pregnancy may be attributed not only to gestational hormones but also possibly to cytokines, which, as mentioned in Section 1, may play a role [28-30]. Increased levels of inflammatory markers such as CRP, plasminogen activator inhibitor-1 (PAI-1), and IL- 6 are predictors of future establishment of type 2 diabetes and CVD [31-34]. Adiponectin, a peptide with antiinflammatory properties, has in some studies been associated with a decreased risk of type 2 diabetes and CVD $[35,36]$.

Markers of endothelial dysfunction, like circulating levels of E-selectin, vascular adhesion molecule-1 (VCAM-1), intercellular adhesion molecule 1 (ICAM-1), as well as inflammatory parameters like CRP and IL-6, have been reported to be associated with CVD in several studies [37-42]. Furthermore, the adhesion molecules E-selectin, VCAM-1, and ICAM-1 are thought to play a major role in the pathogenesis of vascular disease [6]. These molecules are markers of endothelial dysfunction and are expressed on the endothelial wall in response to inflammatory mediators. They contribute to the formation of atherosclerotic plaques and can be detected in soluble form in the circulation [43]. More reliable, and thus of great interest, are the measurements of carotid intima media thickness (IMT) and flow-mediated vasodilatation (FMD). Both indexes have been used in epidemiological studies as surrogate markers of early atherosclerosis. Carotid IMT increases with age, is correlated with cardiovascular risk factors, and identifies subjects at increased risk of severe coronary artery disease and cardiovascular morbidity [37]. Intima media thickness (IMT) is an ultrasound marker of CVD risk. Heiss et al. in their study found positive relation of this marker to cardiovascular risk factors and CVD risk [44].

Mediators of inflammation may exert pathologic action by inducing vascular dysfunction, thus leading to many of the diverse effects of the insulin resistance condition, like hypertension, dyslipidemia, and impaired fibrinolysis [62]. Insulin resistance has been associated with impaired endothelial function, which interacts with coagulation and hypofibrinolysis [63, 64], while hypofibrinolysis and procoagulant activity are linked with increased risk for cardiovascular events (Table 1). It is of note that raised levels of circulating inhibitors of the fibrinolytic system have been observed in patients with insulin resistance [64]. Plasminogen activator inhibitor-1 (PAI-1) is elevated in a variety of clinical situations that are associated with insulin resistance and cardiovascular disorders [65].

Osteoprotegerin (OPG) is a glycoprotein, a soluble member of the tumor necrosis factor (TNF) receptor superfamily, which inhibits receptor activator of nuclear-factor- $\kappa \mathrm{B}$-ligand (RANKL-) mediated osteoclastic bone resorption [66]. It has been reported to be expressed in the arterial wall [67]. Elevated serum OPG levels have been found to be associated with atherosclerosis [68]. 
TABLE 1: Markers of increased CVD risk in normoglycemic women with GDM or pGDM.

\begin{tabular}{|c|c|c|c|}
\hline Authors & Number of subjects & Months/years postpartum & Markers of CVD risk \\
\hline Kousta et al., 2003 [45] & 78 & 3 years & $\begin{array}{l}\uparrow \text { Insulin resistance } \\
\uparrow \text { lipidemia }\end{array}$ \\
\hline Anastasiou et al., 1998 [46] & 68 & 3-6 months & $\downarrow$ FMD \\
\hline Hu et al., 1998 [47] & 37 & $2-4$ years & $\begin{array}{l}\downarrow \text { Acetylcholine induced } \\
\text { vasodilatation }\end{array}$ \\
\hline Knock et al., 1997 [48] & 32 & During cesarean section & $\begin{array}{l}\uparrow \text { Vascular pathology, vessel } \\
\text { myography }\end{array}$ \\
\hline Paradisi et al., 2002 [49] & 38 & During GDM pregnancy & $\downarrow$ FMD \\
\hline Heitritter et al., 2005 [50] & 48 & 1 year & $\downarrow$ Adiponectin \\
\hline Winzer et al., 2004 [51] & 108 & 3 months & $\downarrow$ Adiponectin \\
\hline Bo et al., 2007 [52] & 195 & $6-7$ years & $\begin{array}{l}\uparrow \text { E-selectin } \\
\uparrow \text { ICAM-1 } \\
\uparrow \text { IMT }\end{array}$ \\
\hline Thomaseth et al., 1997 [53] & 10 & 1 year & $\begin{array}{l}\uparrow \text { E-selectin } \\
\uparrow \text { VCAM-1 }\end{array}$ \\
\hline Lawrence et al., 2002 [54] & 265 & recent GDM & $\approx$ E-selectin \\
\hline Kautzky-Willer et al., 1997 [55] & 41 & 3 months & $\begin{array}{l}\uparrow \text { E-selectin } \\
\uparrow \text { VCAM-1 }\end{array}$ \\
\hline Shah et al., 2008 [56] & 89.500 & $\mathrm{p}$ GDM & $\uparrow \mathrm{CVD}$ events \\
\hline Akinci et al., 2008 [57] & 76 & $\mathrm{p}$ GDM & $\begin{array}{l}\uparrow \mathrm{OPG} \\
\uparrow \mathrm{IMT}\end{array}$ \\
\hline Akinci et al., 2011 [58] & 195 & 3 years & $\uparrow \mathrm{OPG}$ \\
\hline Banerjee et al., 2011 [59] & 29 & 2 years & $\begin{array}{l}\uparrow \text { Vascular pathology, vessel } \\
\text { myography }\end{array}$ \\
\hline Farhan et al., 2006 [60] & 70 & recent GDM & $\uparrow \mathrm{PAI}-1$ \\
\hline Madarász et al., 2009 [61] & 107 & 4 years & $\begin{array}{l}\uparrow \text { CVD risk factors, disturbed } \\
\text { carbohydrate metabolism }\end{array}$ \\
\hline
\end{tabular}

Vessel stiffness measured by arterial tonometry is associated with endothelial dysfunction and increased CVD risk $[69,70]$.

\section{Studies in pGDM Women for Identification of the Risk of Cardiovascular Complications}

The study of women in the pGDM state serves as a model for the detection of early metabolic abnormalities. Normoglycemic women with pGDM have increased insulin resistance and decreased endothelium-dependent vasodilatation when compared with women who had uncomplicated pregnancies $[45,46]$. During the first 3-6 months postpartum, women with $\mathrm{PGDM}$ had impaired endothelial function assessed by FMD, this tending to confirm the assumption that glucose metabolism derangement is closely related to vascular dysfunction [46]. A cross-sectional study showed that 2-4 years after the postpartum period, pGDM had impaired acetylcholine-induced skin vasodilatation in hand and foot, as assessed by laser Doppler flow, when compared with normal controls [47]. Two cohort studies have reported signs of vascular endothelial dysfunction in vitro and in vivo during pregnancies complicated by GDM. The first study evaluated vascular endothelial function in small subcutaneous arteries dissected from biopsies obtained at cesarean section using vessel myograph and the second during pregnancy with impaired glucose tolerance and gestational diabetes mellitus assessing brachial artery FMD $[48,49]$.

Heitritter et al. compared biochemical and hemodynamic surrogate markers of CVD in nondiabetic women with and without a history of GDM who were at least one year postpartum and concluded that nondiabetic women with pGDM have evidence of subclinical inflammation, hypoadiponectinemia, and early vascular dysfunction and may be at increased risk of developing CVD [50]. Lower plasma adiponectin concentrations characterize women with $\mathrm{pGDM}$ by contrast to controls, independently of the prevailing insulin sensitivity or the degree of obesity and are associated with subclinical inflammation and atherogenic parameters [51]. Bo et al. showed in their study that pGDM women had higher values of markers of endothelial dysfunction and IMT than controls and an increased future CVD risk; however, few data are available concerning the association between pGDM and inflammation markers of endothelial dysfunction [52]. E-selectin and VCAM-1 concentrations were found to be elevated in a cohort study of women with pGDM one year after delivery [53]. A larger study many months postpartum failed to display the same results 
[54]. Kautzky-Willer et al. demonstrated that pGDM was characterized by persistently raised levels of E-selectin and VCAM-1 12 weeks after delivery [55]. In a large populationbased study, women who had GDM in pregnancy compared with controls were at higher risk of CVD events [56].

Akinci et al. observed that OPG serum levels tended to be elevated in PGDM and moreover reported an association with carotid IMT, thus showing that osteoprotegerin may play a role in the pathogenesis of endothelial dysfunction in these women [57]. Furthermore, a very recent study conducted by the same group concluded that OPG was related to CVD risk factors and metabolic syndrome and may be involved in the development of CVD disorders in pGDM [58]. Farhan et al. recorded elevated PAI-1 levels in pGDM [60].

Another study examined the relationship between glycemia during pregnancy and small artery function 2 years postpartum. In this study subcutaneous arteries from gluteal fat biopsy were examined as to structure, stiffness, and vasoconstrictor response using myography. The results showed that vascular pathology is detectable very early in women at risk of type 2 diabetes [59]. Studying the prevalence of abnormal glucose tolerance and metabolic syndrome in a cohort of pGDM, the results demonstrated disturbed carbohydrate metabolism and a clustering of CVD factors in these women $[61,71]$.

Surrogate markers of increased cardiovascular risk in population-based studies are commonly used in routine practice. However, though in studies of pGDM markers are used that link this condition with future CVD risk [72], the evidence is as yet inadequate for the markers to be applied in the routine followup of these women. Nevertheless, the aforementioned studies are promising, as several of these biochemical and hemodynamic markers may in future prove to be of great value in follow-up programs, contributing to reducing the risk in pGDM for cardiovascular morbidities later in life.

\section{Conclusions}

It has been shown that women with pGDM are more insulin resistant than women with normal carbohydrate tolerance during their pregnancies. Diabetic complications may be in progress during the phase of insulin resistance in pregnancy even in the absence of hyperglycemia, while furthermore there is evidence that pGDM is associated with postpartum diabetes, insulin resistance, hypertension, and dyslipidemia. A history of pGDM can increase the risk of developing not only type 2 diabetes mellitus, which is a major risk factor for the development of cardiovascular disorders, but also CVD independent of the presence of type 2 diabetes. Also mentioned in this paper is the fact that a number of studies have reported pGDM to be additionally associated with the increased prevalence of metabolic syndrome, an important factor of cardiovascular disorders.

Having reviewed the current literature concerning the relationship between inflammatory markers, metabolic abnormalities, and vascular dysfunction in pGDM, we proceeded to evaluate, for the first time to our knowledge, the sum total of this information for the purpose of seeking to identify women at future risk. We additionally reviewed the current knowledge on normal metabolic modifications that occur in pregnancy and the link between these normal modifications and the ensuing long-term complications in this group of women. Based on the evidence related to PGDM, we suggest that these women be considered at an increased risk for subsequent cardiovascular morbidity. Identifying women at increased risk for developing cardiovascular morbidities and, at a later date, placing them in follow-up programs that will include the use of established selected markers, has the potential to substantially hold back their CVD risk in terms of both, lower incidence and reduced severity of cardiovascular events later in life.

\section{References}

[1] L. Jovanovic, R. H. Knopp, H. Kim et al., "Elevated pregnancy losses at high and low extremes of maternal glucose in early normal and diabetic pregnancy: evidence for a protective adaptation in diabetes," Diabetes Care, vol. 28, no. 5, pp. 11131117, 2005.

[2] L. Hoffman, "Gestational diabetes mellitus (GDM)," The Medical journal of Australia, vol. 168, no. 3, p. 140, 1998.

[3] A. C. Richardson and M. W. Carpenter, "Inflammatory mediators in gestational diabetes mellitus," Obstetrics and Gynecology Clinics of North America, vol. 34, no. 2, pp. 213-224, 2007.

[4] E. A. Ryan, S. Imes, D. Liu et al., "Defects in insulin secretion and action in women with a history of gestational diabetes," Diabetes, vol. 44, no. 5, pp. 506-512, 1995.

[5] K. Y. Lain and P. M. Catalano, "Metabolic changes in pregnancy," Clinical Obstetrics and Gynecology, vol. 50, no. 4, pp. 938-948, 2007.

[6] C. J. Petry, "Gestational diabetes: risk factors and recent advances in its genetics and treatment," British Journal of Nutrition, vol. 104, no. 6, pp. 775-787, 2010.

[7] M. H. Hollander, K. M. Paarlberg, and A. J. M. Huisjes, "Gestational diabetes: a review of the current literature and guidelines," Obstetrical and Gynecological Survey, vol. 62, no. 2, pp. 125-136, 2007.

[8] N. Vrachnis, S. Iliodromiti, E. Samoli, Z. Iliodromiti, S. Dendrinos, and G. Creatsas, "Maternal mortality in Greece, 1996-2006," International Journal of Gynecology and Obstetrics, vol. 115, no. 1, pp. 16-19, 2011.

[9] N. Vitoratos, N. Vrachnis, G. Valsamakis, K. Panoulis, and G. Creatsas, "Perinatal mortality in diabetic pregnancy," Annals of the New York Academy of Sciences, vol. 1205, pp. 94-98, 2010.

[10] N. Pérez-Ferre, M. Galindo, M. D. Fernández et al., "The outcomes of gestational diabetes mellitus after a telecare approach are not inferior to traditional outpatient clinic visits," International Journal of Endocrinology, vol. 2010, Article ID 386941, 6 pages, 2010.

[11] B. R. Vohr and C. M. Boney, "Gestational diabetes: the forerunner for the development of maternal and childhood obesity and metabolic syndrome?" Journal of Maternal-Fetal and Neonatal Medicine, vol. 21, no. 3, pp. 149-157, 2008.

[12] D. Getahun, C. Nath, C. V. Ananth, M. R. Chavez, and J. C. Smulian, "Gestational diabetes in the United States: temporal trends 1989 through 2004," American Journal of Obstetrics and Gynecology, vol. 198, no. 5, p. 525, 2008.

[13] C. Kim, K. M. Newton, and R. H. Knopp, "Gestational diabetes and the incidence of type 2 diabetes: a systematic review," Diabetes Care, vol. 25, no. 10, pp. 1862-1868, 2002. 
[14] I. Lambrinoudaki, S. A. Vlachou, and G. Creatsas, "Genetics in gestational diabetes mellitus: association with incidence, severity, pregnancy outcome and response to treatment," Current diabetes reviews, vol. 6, no. 6, pp. 393-399, 2010.

[15] K. M. Fox, H. W. Rodbard, A. J. Green, and S. Grandy, "Trends in method of diagnosis of type 2 diabetes mellitus: results from SHIELD," International Journal of Endocrinology, vol. 2009, Article ID 796206, 6 pages, 2009.

[16] B. E. Metzger, N. H. Cho, S. M. Roston, and R. Radvany, "Prepregnancy weight and antepartum insulin secretion predict glucose tolerance five years after gestational diabetes mellitus," Diabetes Care, vol. 16, no. 12, pp. 1598-1605, 1993.

[17] R. C. Kaufmann, F. T. Schleyhahn, D. G. Huffman, and K. S. Amankwah, "Gestational diabetes diagnostic criteria: longterm maternal follow-up," American Journal of Obstetrics and Gynecology, vol. 172, no. 2 I, pp. 621-625, 1995.

[18] K. T. Khaw, N. Wareham, S. Bingham, R. Luben, A. Welch, and N. Day, "Association of hemoglobin Alc with cardiovascular disease and mortality in adults: the European prospective investigation into cancer in Norfolk," Annals of Internal Medicine, vol. 141, no. 6, pp. 413-420, 2004.

[19] M. L. Daviglus, K. Liu, L. L. Yan et al., "Relation of body mass index in young adulthood and middle age to medicare expenditures in older age," Journal of the American Medical Association, vol. 292, no. 22, pp. 2743-2749, 2004.

[20] J. Lauenborg, E. Mathiesen, T. Hansen et al., "The prevalence of the metabolic syndrome in a Danish population of women with previous gestational diabetes mellitus is three-fold higher than in the general population," Journal of Clinical Endocrinology and Metabolism, vol. 90, no. 7, pp. 4004-4010, 2005.

[21] D. B. Carr, K. M. Utzschneider, R. L. Hull et al., "Gestational diabetes mellitus increases the risk of cardiovascular disease in women with a family history of type 2 diabetes," Diabetes Care, vol. 29, no. 9, pp. 2078-2083, 2006.

[22] E. Tarim, F. Yigit, E. Kilicdag et al., "Early onset of subclinical atherosclerosis in women with gestational diabetes mellitus," Ultrasound in Obstetrics and Gynecology, vol. 27, no. 2, pp. 177-182, 2006.

[23] V. A. Fonseca, "Management of diabetes mellitus and insulin resistance in patients with cardiovascular disease," The American journal of cardiology, vol. 92, no. 4 A, pp. 50J-60J, 2003.

[24] J. B. O’Sullivan, "Diabetes mellitus after GDM," Diabetes, vol. 40, 2, pp. 131-135, 1991.

[25] R. Ross, "Atherosclerosis-an inflammatory disease," The New England Journal of Medicine, vol. 340, no. 2, pp. 115-126, 1999.

[26] J. Danesh, J. G. Wheeler, G. M. Hirschfield et al., "C-Reactive protein and other circulating markers of inflammation in the prediction of coronary heart disease," New England Journal of Medicine, vol. 350, no. 14, pp. 1387-1397, 2004.

[27] G. D. O. Lowe, A. Rumley, A. D. McMahon, I. Ford, D. S. J. O'Reilly, and C. J. Packard, "Interleukin-6, fibrin D-dimer, and coagulation factors VII and XIIa in prediction of coronary heart disease," Arteriosclerosis, Thrombosis, and Vascular Biology, vol. 24, no. 8, pp. 1529-1534, 2004.

[28] P. M. Ridker, C. H. Hennekens, J. E. Buring, and N. Rifai, "C-reactive protein and other markers of inflammation in the prediction of cardiovascular disease in women," New England Journal of Medicine, vol. 342, no. 12, pp. 836-843, 2000.

[29] D. J. Freeman, J. Norrie, M. J. Caslake et al., "C-reactive protein is an independent predictor of risk for the development of diabetes in the west of Scotland coronary prevention study," Diabetes, vol. 51, no. 5, pp. 1596-1600, 2002.

[30] A. Festa, R. D’Agostino, G. Howard, L. Mykkänen, R. P. Tracy, and S. M. Haffner, "Chronic subclinical inflammation as part of the insulin resistance syndrome: the insulin resistance atherosclerosis study (IRAS)," Circulation, vol. 102, no. 1, pp. 4247, 2000.

[31] W. Koenig, H. Löwel, J. Baumert, and C. Meisinger, "C-reactive protein modulates risk prediction based on the framingham score-implications for future risk assessment: results from a large cohort study in Southern Germany," Circulation, vol. 109, no. 11, pp. 1349-1353, 2004.

[32] A. Hamsten, G. Walldius, and A. Szamosi, "Plasminogen activator inhibitor in plasma: risk factor for recurrent myocardial infarction," Lancet, vol. 2, no. 8549, pp. 3-9, 1987.

[33] N. S. Jenny, R. P. Tracy, M. S. Ogg et al., "In the elderly, interleukin-6 plasma levels and the $-174 \mathrm{G}>\mathrm{C}$ polymorphism are associated with the development of cardiovascular disease," Arteriosclerosis, Thrombosis, and Vascular Biology, vol. 22, no. 12, pp. 2066-2071, 2002.

[34] P. L. Sanchez, J. L. Morinigo, P. Pabon et al., "Prognostic relations between inflammatory markers and mortality in diabetic patients with non-ST elevation acute coronary syndrome," Heart, vol. 90, no. 3, pp. 264-269, 2004.

[35] K. M. Choi, J. Lee, K. W. Lee et al., "Serum adiponectin concentrations predict the developments of type 2 diabetes and the metabolic syndrome in elderly Koreans," Clinical Endocrinology, vol. 61, no. 1, pp. 75-80, 2004.

[36] T. Pischon, C. J. Girman, G. S. Hotamisligil, N. Rifai, F. B. Hu, and E. B. Rimm, "Plasma adiponectin levels and risk of myocardial infarction in men," Journal of the American Medical Association, vol. 291, no. 14, pp. 1730-1737, 2004.

[37] L. E. Rohde, T. L. Richard, J. Rivero et al., "Circulating cell adhesion molecules are correlated with ultrasound-based assessment of carotid atherosclerosis," Arteriosclerosis, Thrombosis, and Vascular Biology, vol. 18, no. 11, pp. 1765-1770, 1998.

[38] I. M. Van Der Meer, M. P. M. De Maat, M. L. Bots et al., "Inflammatory mediators and cell adhesion molecules as indicators of severity of atherosclerosis: the Rotterdam study," Arteriosclerosis, Thrombosis, and Vascular Biology, vol. 22, no. 5, pp. 838-842, 2002.

[39] P. Libby, P. M. Ridker, and A. Maseri, "Inflammation and atherosclerosis," Circulation, vol. 105, no. 9, pp. 1135-1143, 2002.

[40] A. D. Pradhan, N. Rifai, and P. M. Ridker, "Soluble intercellular adhesion molecule-1, soluble vascular adhesion molecule1 , and the development of symptomatic peripheral arterial disease in men," Circulation, vol. 106, no. 7, pp. 820-825, 2002.

[41] K. Kondo, K. Kitagawa, Y. Nagai et al., "Associations of soluble intercellular adhesion molecule-1 with carotid atherosclerosis progression," Atherosclerosis, vol. 179, no. 1, pp. 155-160, 2005.

[42] I. Tzoulaki, G. D. Murray, A. J. Lee, A. Rumley, G. D. O. Lowe, and F. G. R. Fowkes, "C-reactive protein, interleukin6 , and soluble adhesion molecules as predictors of progressive peripheral atherosclerosis in the general population: Edinburgh artery study," Circulation, vol. 112, no. 7, pp. 976-983, 2005.

[43] A. J. H. Gearing, I. Hemingway, R. Pigott, J. Hughes, A. J. Rees, and S. J. Cashman, "Soluble forms of vascular adhesion molecules, E-selectin, ICAM-1, and VCAM-1: pathological significance," Annals of the New York Academy of Sciences, vol. 667, pp. 324-331, 1992.

[44] G. Heiss, A. R. Sharrett, R. Barnes, L. E. Chambless, M. Szklo, and C. Alzola, "Carotid atherosclerosis measured by B-mode ultrasound in populations: associations with cardiovascular 
risk factors in the ARIC study," American Journal of Epidemiology, vol. 134, no. 3, pp. 250-256, 1991.

[45] E. Kousta, N. J. Lawrence, I. F. Godsland et al., "Insulin resistance and $\beta$-cell dysfunction in normoglycaemic European women with a history of gestational diabetes," Clinical Endocrinology, vol. 59, no. 3, pp. 289-297, 2003.

[46] E. Anastasiou, J. P. Lekakis, M. Alevizaki et al., "Impaired endothelium-dependent vasodilatation in women with previous gestational diabetes," Diabetes Care, vol. 21, no. 12, pp. 2111-2115, 1998.

[47] J. Hu, M. Norman, M. Wallensteen, and G. Gennser, "Increased large arterial stiffness and impaired acetylcholine induced skin vasodilatation in women with previous gestational diabetes mellitus," British Journal of Obstetrics and Gynaecology, vol. 105, no. 12, pp. 1279-1287, 1998.

[48] G. A. Knock, A. L. McCarthy, C. Lowy, and L. Poston, "Association of gestational diabetes with abnormal maternal vascular endothelial function," British Journal of Obstetrics and Gynaecology, vol. 104, no. 2, pp. 229-234, 1997.

[49] G. Paradisi, A. Biaggi, S. Ferrazzani, S. De Carolis, and A. Caruso, "Abnormal carbohydrate metabolism during pregnancy: association with endothelial dysfunction," Diabetes Care, vol. 25, no. 3, pp. 560-564, 2002.

[50] S. M. Heitritter, C. G. Solomon, G. F. Mitchell, N. Skali-Ounis, and E. W. Seely, "Subclinical inflammation and vascular dysfunction in women with previous gestational diabetes mellitus," Journal of Clinical Endocrinology and Metabolism, vol. 90, no. 7, pp. 3983-3988, 2005.

[51] C. Winzer, O. Wagner, A. Festa et al., "Plasma adiponectin, insulin sensitivity, and subclinical inflammation in women with prior gestational diabetes mellitus," Diabetes Care, vol. 27, no. 7, pp. 1721-1727, 2004.

[52] S. Bo, S. Valpreda, G. Menato et al., "Should we consider gestational diabetes a vascular risk factor?" Atherosclerosis, vol. 194, no. 2, pp. e72-e79, 2007.

[53] K. Thomaseth, G. Pacini, M. Clodi et al., "Amylin release during oral glucose tolerance test," Diabetic Medicine, vol. 14, no. 2, pp. S29-S34, 1997.

[54] N. J. Lawrence, E. Kousta, A. Penny et al., "Elevation of soluble E-selectin levels following gestational diabetes is restricted to women with persistent abnormalities of glucose regulation," Clinical Endocrinology, vol. 56, no. 3, pp. 335-340, 2002.

[55] A. Kautzky-Willer, P. Fasching, B. Jilma, W. Waldhäusl, and O. F. Wagner, "Persistent elevation and metabolic dependence of circulating E-selectin after delivery in women with gestational diabetes mellitus," Journal of Clinical Endocrinology and Metabolism, vol. 82, no. 12, pp. 4117-4121, 1997.

[56] B. R. Shah, R. Retnakaran, and G. L. Booth, "Increased risk of cardiovascular disease in young women following gestational diabetes mellitus," Diabetes Care, vol. 31, no. 8, pp. 1668-1669, 2008.

[57] B. Akinci, T. Demir, A. Celtik et al., "Serum osteoprotegerin is associated with carotid intima media thickness in women with previous gestational diabetes," Diabetes Research and Clinical Practice, vol. 82, no. 2, pp. 172-178, 2008.

[58] B. Akinci, A. Celtik, F. Yuksel et al., "Increased osteoprotegerin levels in women with previous gestational diabetes developing metabolic syndrome," Diabetes Research and Clinical Practice, vol. 91, no. 1, pp. 26-31, 2011.

[59] M. Banerjee, S. G. Anderson, R. A. Malik, C. E. Austin, and J. K. Cruickshank, "Small artery function 2 years postpartum in women with altered glycaemic distributions in their preceding pregnancy," Clinical Science, vol. 122, no. 2, pp. 53-61, 2012.
[60] S. Farhan, C. Winzer, A. Tura et al., "Fibrinolytic dysfunction in insulin-resistant women with previous gestational diabetes," European Journal of Clinical Investigation, vol. 36, no. 5, pp. 345-352, 2006.

[61] E. Madarász, G. Tamás, A. Gy. Tabák, and Z. Kerényi, "Carbohydrate metabolism and cardiovascular risk factors 4 years after a pregnancy complicated by gestational diabetes," Diabetes Research and Clinical Practice, vol. 85, no. 2, pp. 197-202, 2009.

[62] J. B. Meigs, F. B. Hu, N. Rifai, and J. E. Manson, "Biomarkers of Endothelial Dysfunction and Risk of Type 2 Diabetes Mellitus," Journal of the American Medical Association, vol. 291, no. 16, pp. 1978-1986, 2004.

[63] H. Yki-Järvinen, "Insulin resistance and endothelial dysfunction," Best Practice and Research: Clinical Endocrinology and Metabolism, vol. 17, no. 3, pp. 411-430, 2003.

[64] P. J. Grant, "Diabetes mellitus as a prothrombotic condition," Journal of Internal Medicine, vol. 262, no. 2, pp. 157-172, 2007.

[65] I. Juhan-Vague and M. C. Alessi, "PAI-1, obesity, insulin resistance and risk of cardiovascular events," Thrombosis and Haemostasis, vol. 78, no. 1, pp. 656-660, 1997.

[66] H. Min, S. Morony, I. Sarosi et al., "Osteoprotegerin reverses osteoporosis by inhibiting endosteal osteoclasts and prevents vascular calcification by blocking a process resembling osteoclastogenesis," Journal of Experimental Medicine, vol. 192, no. 4, pp. 463-474, 2000.

[67] C. R. Dhore, J. P. M. Cleutjens, E. Lutgens et al., "Differential expression of bone matrix regulatory proteins in human atherosclerotic plaques," Arteriosclerosis, Thrombosis, and Vascular Biology, vol. 21, no. 12, pp. 1998-2003, 2001.

[68] M. Abedin, T. Omland, T. Ueland et al., "Relation of Osteoprotegerin to Coronary Calcium and Aortic Plaque (from the Dallas Heart Study)," American Journal of Cardiology, vol. 99, no. 4, pp. 513-518, 2007.

[69] A. Nigam, G. F. Mitchell, J. Lambert, and J. C. Tardif, "Relation between conduit vessel stiffness (assessed by tonometry) and endothelial function (assessed by flow-mediated dilatation) in patients with and without coronary heart disease," American Journal of Cardiology, vol. 92, no. 4, pp. 395-399, 2003.

[70] T. Weber, J. Auer, M. F. O’Rourke et al., "Arterial Stiffness, Wave Reflections, and the Risk of Coronary Artery Disease," Circulation, vol. 109, no. 2, pp. 184-189, 2004.

[71] G. Di Cianni, A. Ghio, V. Resi, and L. Volpe, "Gestational diabetes mellitus: an opportunity to prevent type 2 diabetes and cardiovascular disease in young women," Women's Health, vol. 6, no. 1, pp. 97-105, 2010.

[72] R. Bentley-Lewis, "Late cardiovascular consequences of gestational diabetes mellitus," Seminars in Reproductive Medicine, vol. 27, no. 4, pp. 322-329, 2009. 


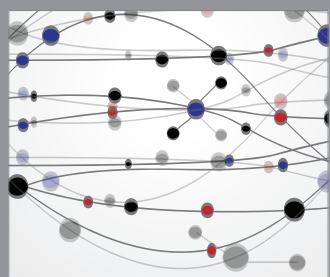

The Scientific World Journal
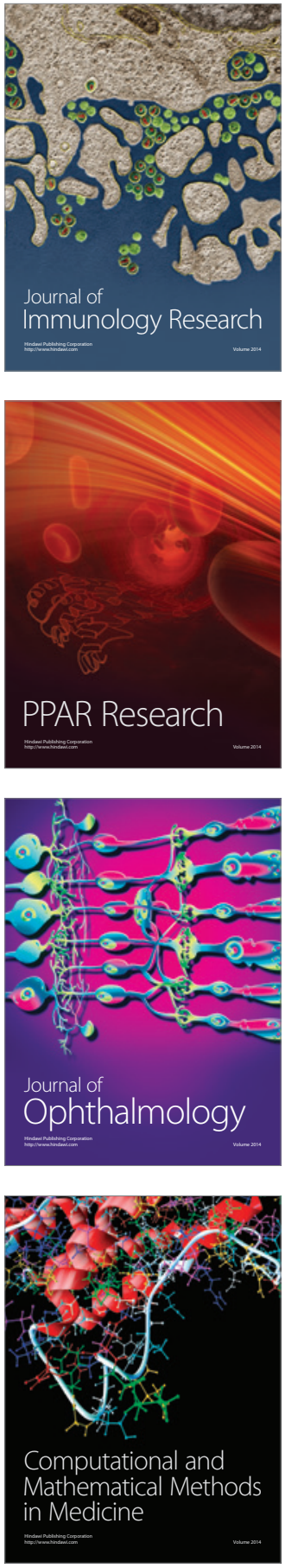

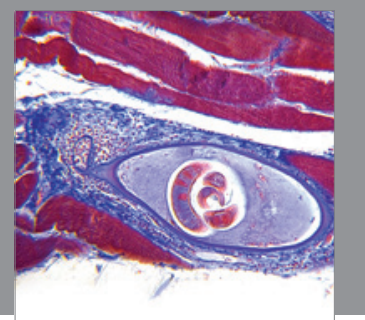

Gastroenterology

Research and Practice
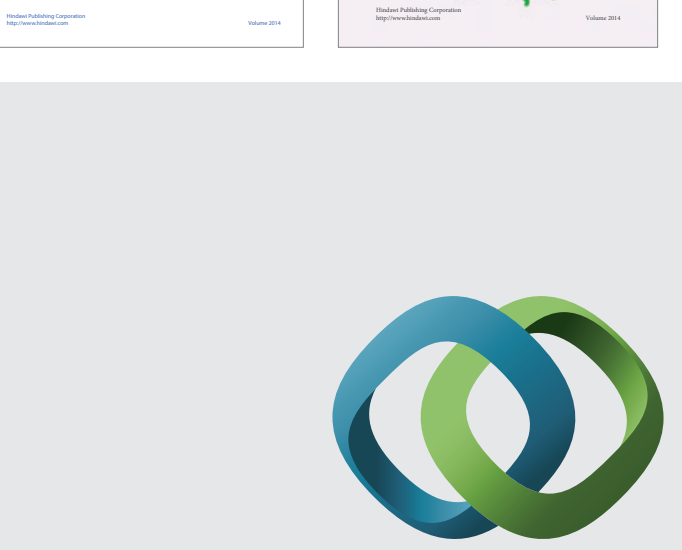

\section{Hindawi}

Submit your manuscripts at

http://www.hindawi.com
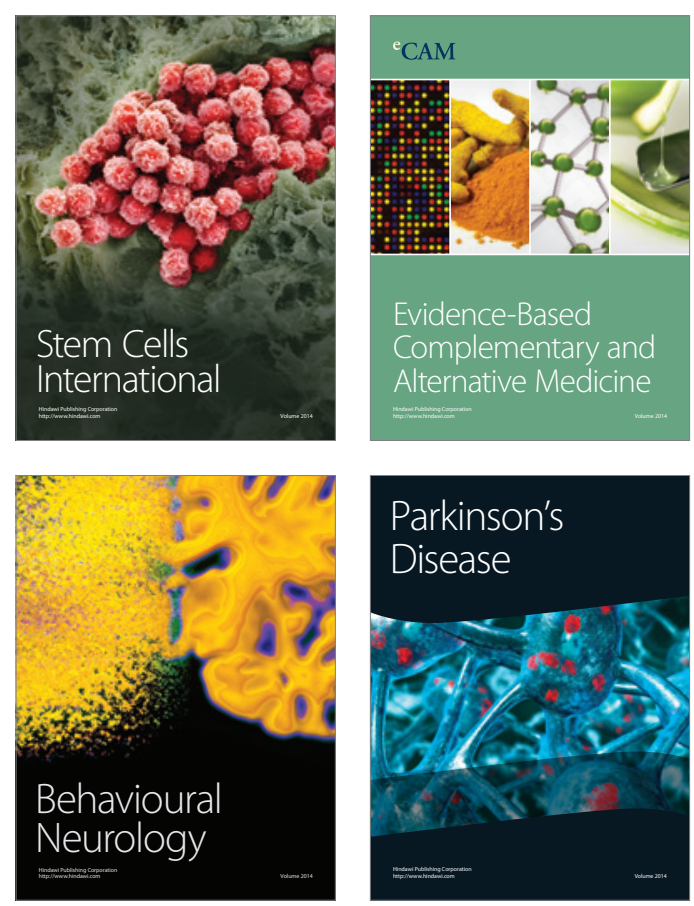

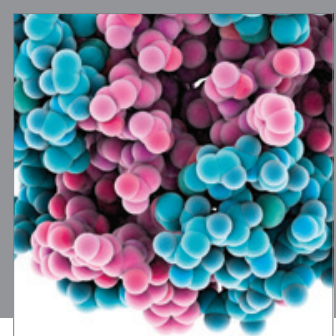

Journal of
Diabetes Research

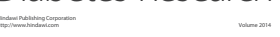

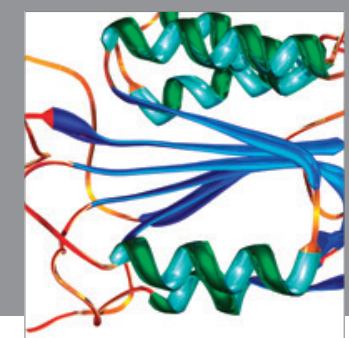

Disease Markers
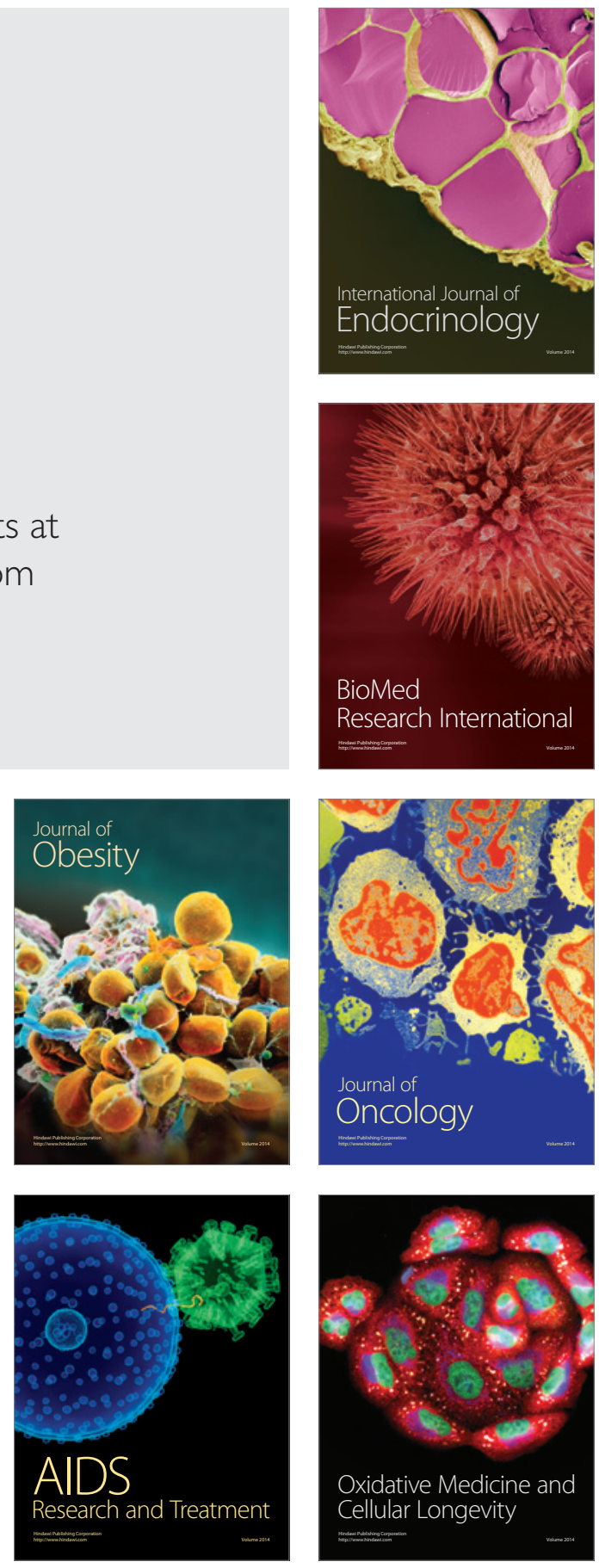